\title{
Quality and reliability of optical coatings
}

\author{
C L NAGENDRA and G K M THUTUPALLI \\ ISRO Satellite Centre, Bangalore 560017 , India
}

\begin{abstract}
Quality and reliability of optical coatings can be evaluated by studying their basic and durability properties. A simple experimental technique is developed which facilitates easy and quick estimation of the quality and reliability of optical coatings as well as optimization of process parameters. This technique has been successfully applied for process optimization of anti-reflection coatings (ARCS) for Ge optics in the IR region.
\end{abstract}

Keywords. Optical coating; anti-reflection coatings; germanium.

\section{Introduction}

In the early 60 s optical coatings were confined to simple systems such as reflectors and antireflection coatings whose applications were limited in nature. In recent years, the science and technology of optical coatings have undergone remarkable changes resulting in the development of a variety of optical coatings ranging from simple coatings to semiconductor, dielectric and refractory coatings. Since quality and durability are the basic factors responsible for satisfactory performance of system, along with the growth and necessity of variety of optical coatings, their quality and reliability also have become equally important. Therefore, development of high quality and reliable coatings for a particular application needs a better understanding of the coating materials and their associated process technology.

Quality and reliability of any system, in general, are assessed in terms of its performance, under given environmental conditions. Hence, to evaluate the quality and reliability of optical coatings, it is necessary to study their behaviour under given environs. This calls for a detailed investigation of the physical properties of the coatings. We have studied different physical properties which reflect the quality and reliability of optical coatings and the experimental techniques to evaluate such parameters. Based on this, a simple experimental method has been developed to demonstrate their quality and reliability. In this paper, different physical properties of the coatings, salient features of the new experimental technique and its results are presented.

\section{Physical properties of optical coatings}

Different physical properties of optical coatings that are normally considered are spectral characteristics such as reflectance, transmittance and absorptance, mechanical properties such as hardness, adhesion, abrasion resistance and durability properties such as ageing characteristics under high humidity, salinity and extreme temperature conditions. These, as a whole, can be broadly classified into basic and durability properties. 


\subsection{Basic properties}

In optical coatings, spectral characteristics form the basis of their development. The materials and the process parameters are chosen so as to meet the required optical properties. Since coatings are normally deposited on optical elements such as lenses, wedges and plane parallel plates known as substrates, the deposited coatings should have satisfactory adhesion to the substrate. The optical properties and mechanical adhesion can, therefore, be considered as the basic properties.

\subsection{Durability properties}

For given conditions, the coatings should have reliable performance over a specified length of time. By studying the durability properties, it is possible to know whether they are capable of withstanding the particular environment over a given duration. In this study, the coatings are exposed to the specified environmental conditions and the basic properties are verified for any significant change. This will give the time after which the coatings will show signs of deterioration. Considering the various external conditions that the coatings are subjected to, the total number of tests could be enormous. However, to rationalize and follow certain standard test procedures, military specifications are universally adopted (Guenther 1981).

The coating properties, in general, depend on the choice of the materials used for preparing the coating and on the process parameters such as cleaning procedures and method of evaporation. The properties affected by different process parameters are presented in table 1 (Ritter 1981). It is seen that to produce good coatings, it is necessary to optimize these parameters and ascertain their durability/reliability of the coatings by conducting accelerated life tests according to military standards. Considering the various test procedures followed in military standards and process parameters, the task of optimization and demonstration of quality and reliability becomes stupendous. Hence, simplification of the test procedures greatly helps in this direction. The

Table 1. Influence of process parameters on coating properties

\begin{tabular}{|c|c|c|c|c|c|c|}
\hline $\begin{array}{l}\text { Coating } \\
\text { property }\end{array}$ & $\begin{array}{c}\text { Substrate } \\
\text { cleaning }\end{array}$ & $\begin{array}{c}\text { Ionic } \\
\text { cleaning }\end{array}$ & $\begin{array}{l}\text { Evapor- } \\
\text { ation } \\
\text { method }\end{array}$ & $\begin{array}{c}\text { Evapor- } \\
\text { ation } \\
\text { rate }\end{array}$ & $\begin{array}{c}\text { High } \\
\text { vaccum } \\
\text { pressure }\end{array}$ & $\begin{array}{c}\text { Substrate } \\
\text { temper- } \\
\text { ature }\end{array}$ \\
\hline Ref. index & - & - & - & $\mathbf{A}^{+}$ & $\mathbf{A}^{+}$ & $\mathbf{A}^{+}$ \\
\hline $\begin{array}{l}\text { Transmission } \\
\text { absorption }\end{array}$ & - & - & A & $\mathbf{A}^{-}$ & A & A \\
\hline Stress & $A^{-}$ & $A^{-}$ & - & $\mathbf{A}^{-}$ & $A^{-}$ & $A^{*}$ \\
\hline Adherence & $\mathbf{A}^{+}$ & $\mathbf{A}$ & - & $\mathbf{A}$ & $\mathbf{A}^{+}$ & $\mathbf{A}^{+}$ \\
\hline $\begin{array}{l}\text { Temperature } \\
\text { stability }\end{array}$ & $A$ & - & - & A & A & $\mathrm{A}^{+}$ \\
\hline Insolubility & $\mathrm{A}^{-}$ & - & - & $A^{-}$ & $\mathbf{A}$ & $A^{+}$ \\
\hline $\begin{array}{l}\text { Resistance to } \\
\text { radiation }\end{array}$ & A & A & $\mathbf{A}$ & A & A & A \\
\hline Defects & $A$ & $\mathbf{A}$ & $\mathbf{A}^{+}$ & $\mathbf{A}$ & $\mathbf{A}^{-}$ & $\mathbf{A}$ \\
\hline
\end{tabular}

$\mathrm{A}^{+}$, strong dependence; $\mathrm{A}$, moderate dependence; $\mathbf{A}^{-}$, possible dependence. 
proposed experimental technique, because of its composite nature, makes the test and evaluation simpler and at the same time, it also includes the salient features of the majority of the test procedures followed in military specifications. It makes use of simple laboratory facilities.

\section{Boiled water scotch tape test}

The various specifications and standards commonly used for optical coatings are discussed in detail by Guenther (1981). Considering the effect of these tests on the coating properties they can be classified into three groups:

(i) Tests in which effect of solvents/vapours are studied; e.g., humidity, salt spray, boiling water and solubility tests etc.

(ii) Tests in which the effect of temperature is studied; e.g., the temperature cycling and thermal shock tests.

(iii) Radiation resistance tests where the effect of high energy radiations on the coating properties is studied.

Normally after these tests are conducted individually or collectively, basic properties, namely mechanical adhesion and optical properties are studied (sometimes, it is also necessary to conduct abrasion resistance test). The military specification tests basically make use of solvent/vapour environment and extreme temperature conditions. This dual effect of solvent/vapour environment and extreme temperature conditions can be effectively brought about by adopting the boiled water scotch tape test. In this, the samples are immersed in boiled water at regular intervals of 5, 10, 20 minutes etc., cooled to ambient conditions quickly and tested for adhesion using standard scotch tape. The percentage peel-off at each interval of time is recorded by visual observation. By comparing the time intervals at which $50 \%$ coating is peeled off, it is possible to identify the particular group of samples which have higher probability of survival. This essentially demonstrates the reliability of the coatings. Apart from this, the additional advantages of this procedure are:

(i) By studying the mode of failure and its relation to the properties of the coating material and the substrate, it is possible to choose proper evaporation materials for a given substrate.

(ii) Since this test is a combination of humidity, solubility, temperature cycling and thermal shock tests, the observations and its conclusions are helpful in anticipating the behaviour of the coating when subjected to individual tests.

(iii) By extending this test over a large number of samples, reliability figures of optical coatings can be estimated experimentally. This, however, needs a thorough study on the sampling procedure for a given application.

\section{Application to infrared antireflection coatings}

The above method has been applied to optimize the various process parameters of ARCS on $\mathrm{Ge}$, such as temperature, evaporation rate and ionic cleaning time. After depositing the coatings, the boiled water scotch tape test is carried out and the time at which the initial failure starts and $50 \%$ coating peels, are noted down for each sample. The test 
Table 2. Experimental results of boiled water scotch tape test

\begin{tabular}{ccc}
\hline & $\begin{array}{c}\text { Time at } \\
\text { which visual } \\
\text { deterioration } \\
\text { observed } \\
\text { (minutes) }\end{array}$ & $\begin{array}{c}\text { Time at which } \\
50 \% \text { pealing } \\
\text { observed } \\
\text { (minutes) }\end{array}$ \\
\hline Room temp. & 5 & 10 \\
100 & 5 & 10 \\
150 & 10 & 50 \\
200 & 60 & 250 \\
250 & 10 & 50 \\
300 & 10 & 60 \\
\hline
\end{tabular}

The normal adhesion is satisfactory in all cases.

Table 3. Quality and reliability characteristics of anti-refiection coatings (ARCs) on Ge

\begin{tabular}{|c|c|c|c|}
\hline Tests conducted & $\begin{array}{l}\text { Specification } \\
\text { followed }\end{array}$ & Test results & Remarks \\
\hline \multicolumn{4}{|l|}{ Basic properties } \\
\hline Spectral transmission & 一 & $\begin{array}{l}80 \% \text { in } 14-16 \mu \mathrm{m} \\
(100 \% \text { improvement } \\
\text { over bare Ge })\end{array}$ & $\begin{array}{l}\text { Same transmission } \\
\text { levels achieved in other } \\
\text { wavelength }\end{array}$ \\
\hline Spectral reflection & - & $\begin{array}{l}8 \% \text { in } 14-16 \mu \mathrm{m} \\
(90 \% \text { improvement in } \\
\text { reducing the reflection } \\
\text { loss of } \mathrm{Ge})\end{array}$ & $\begin{array}{l}\text { Same reflection } \\
\text { levels achieved in other } \\
\text { wavelength }\end{array}$ \\
\hline Adhesion & MIL-M-13508 & Meets specifications & \\
\hline \multicolumn{4}{|l|}{ Durability properties } \\
\hline $\begin{array}{l}\text { Thermal/cleaning } \\
\text { durability test }\end{array}$ & MIL-F-48616 & Meets specifications & \\
\hline Salt solubility test & $\begin{array}{l}\text { MIL-C-675A } \\
\text { MIL-F-48616 }\end{array}$ & $\begin{array}{l}\text { Meets specifications } \\
\text { Meets specifications }\end{array}$ & \\
\hline Humidity test & $\begin{array}{l}\text { MIL-C-675A } \\
\text { MIL-F-48616 }\end{array}$ & Meets specifications & - \\
\hline Abrasion test & MIL-C-675A & Meets specifications & - \\
\hline \multicolumn{4}{|c|}{ Long term durability properties } \\
\hline Thermal cycling test & $\begin{array}{l}+70^{\circ} \mathrm{C} \text { to }-30^{\circ} \mathrm{C} \\
150 \text { cycles }\end{array}$ & $\begin{array}{l}\text { No change in the basic } \\
\text { properties and passes } \\
\text { abrasion test as per } \\
\text { MIL-C-675A }\end{array}$ & - \\
\hline Thermal soak test & $100^{\circ} \mathrm{C}$ for $24 \mathrm{hr}$ & $\begin{array}{l}\text { No change in the basic } \\
\text { properties and passes } \\
\text { abrasion test as per } \\
\text { MIL-C-675A }\end{array}$ & \\
\hline $\begin{array}{l}\text { Extended salt } \\
\text { solubility test }\end{array}$ & $\begin{array}{l}\text { Total duration } \\
\text { of soaking } \\
125 \mathrm{hr}\end{array}$ & $\begin{array}{l}\text { Passes the test as per } \\
\text { specification MIL-C-675A } \\
\text { and MIL-F-48616 }\end{array}$ & - \\
\hline
\end{tabular}


results with respect to the different substrate temperatures are summarized in table 2 . It is evident that samples deposited at $200^{\circ} \mathrm{C}$ survived for a longer duration without any failure. The corresponding $50 \%$ peel-off time is also about five times greater than for other samples. This indicates that samples deposited at $200^{\circ} \mathrm{C}$ have higher probability of survival and are more reliable than others.

To compare the results of the present test with those of military specification tests, similar samples were subjected to the military specification tests such as salt solubility and humidity tests (MIL-C-675A and MIL-F-48616) and few longer durability tests. The various tests conducted on the samples and the corresponding observations presented in table 3 show that the coated samples not only withstand the military specification tests but are also stable even after long term durability tests. Therefore, it can be concluded that the method can be adopted for process optimization of optical coatings and as a quick look quality control test. It is also very effective in arriving at the optimized process parameters.

\section{References}

Ritter E 1981 Appl. Opt. 2021

Guenther K H 1981 Appl. Opt. 203487 